\title{
Structural color coating films composed of an amorphous array of colloidal particles via electrophoretic deposition
}

\author{
Kiyofumi Katagiri ${ }^{1,3}$, Yuuki Tanaka ${ }^{1}$, Kensuke Uemura ${ }^{1}$, Kei Inumaru ${ }^{1}$, Takahiro Seki ${ }^{2}$ \\ and Yukikazu Takeoka ${ }^{2,3}$
}

It is desirable to fabricate colorful coatings that have nonfading properties and are environmentally friendly. In this study, a novel approach for creating structural color coatings from monodisperse silica particles is presented. The structural color coating films, formed from an array of silica particles with a small amount of black additive, are easily prepared by a simple electrophoretic deposition (EPD) technique. The arrangement of the particle array is controlled by varying the applied voltage and deposition time. The iridescence, that is, the angular dependence, of the structural color dramatically changes with the arrangement of the particle array. A variety of colored coatings can be produced by changing the size of the particles. Structural color coatings on materials with curved surfaces and complicated shapes are also achieved by the EPD method.

NPG Asia Materials (2017) 9, e355; doi:10.1038/am.2017.13; published online 10 March 2017

\section{INTRODUCTION}

Paints, that is, dyes or pigments, are often used in various industries to make colored products. The color of a dye or pigment is an inherent property of the material, which depends on its chemical nature. ${ }^{1,2}$ Some of these paints, especially those containing organic dye molecules, easily fade over time or upon exposure to light. In addition, there is concern over unfavorable influences on health and the environment, as some paints contain harmful substances. Therefore, coloration free from photobleaching or toxic materials is a central goal of paint research.

Structural color is one of the most promising candidates to solve this challenge. ${ }^{3-9}$ Submicrometer-sized microstructures reflect or scatter light so that waves of certain frequencies can constructively interfere to form this type of color. As electronic excitation is not involved in the coloration mechanism, the structural color is not susceptible to fading unless the microstructure is destroyed. The microstructure can be prepared using highly safe chemical substances. The most familiar natural structurally colored material is opal. ${ }^{10}$ Naturally formed precious opals consist of a periodic array of monodisperse silica $\left(\mathrm{SiO}_{2}\right)$ spheres with diameters on the submicrometer scale. Similar structures can also be synthesized artificially in the laboratory. Structural color from particle arrays is advantageous in the sense that the color can be tuned merely by choosing the size of the microstructure without changing the material design. Therefore, many groups have attempted to create artificial periodic arrays of colloidal particles. ${ }^{11-13}$ However, such structural color typically exhibits iridescence, that is, angular dependence, which is unfavorable for general purposes, except in some cases, such as ornamental jewelry and accessories. Ideally, commonly used paints appear the same color regardless of the viewing angle. We can identify the existence of low angle dependence structural color morphologies in nature. Avian feathers, ${ }^{14,15}$ the blue skin of mandrills ${ }^{16}$ and the scales of longhorn beetles $^{17,18}$ are well-known examples of such non-iridescent structural color. Unlike those of precious opal, they possess short-range ordered and long-range random (that is, amorphous) microstructures. Considerable attention has been focused on the preparation of low-angle dependence, structurally colored materials by mimicking such natural examples. The iridescence of colloidal crystals originates from Bragg reflection, ${ }^{11-13}$ which is the reflection mechanism that occurs as a result of long-range order in the particle arrangement. Thus, if the arrangement is changed from a crystalline structure to the amorphous state, which has only short-range order, the iridescence is expected to be suppressed. To create amorphous structures from colloidal assemblies, simple evaporation, centrifugation, drop-casting, spin-coating and spray coating techniques have been commonly employed. ${ }^{19-30}$ For example, we successfully prepared colorful coatings consisting of an amorphous array using mixtures of two different sizes of $\mathrm{SiO}_{2}$ particles by the simple evaporation method. ${ }^{20}$ In addition, we

\footnotetext{
${ }^{1}$ Department of Applied Chemistry, Graduate School of Engineering, Hiroshima University, Higashi-Hiroshima, Hiroshima, Japan and ${ }^{2}$ Department of Molecular Design and Engineering, Graduate School of Engineering, Nagoya University, Furo-cho, Chikusa-ku, Nagoya, Japan

${ }^{3}$ These authors contributed equally to this work.

Correspondence: Professor K Katagiri, Department of Applied Chemistry, Graduate School of Engineering, Hiroshima University, 1-4-1 Kagamiyama, Higashi-Hiroshima, Hiroshima 739-8527, Japan.

E-mail: kktgr@hiroshima-u.ac.jp

or Professor Y Takeoka, Department of Molecular Design and Engineering, Graduate School of Engineering, Nagoya University, Furo-cho, Chikusa-ku, Nagoya 464-8603, Japan. E-mail: ytakeoka@apchem.nagoya-u.ac.jp

Received 20 September 2016; revised 20 December 2016; accepted 3 January 2017
} 
fabricated a colloidal amorphous array of $\mathrm{SiO}_{2}$ particles by spray coating. ${ }^{21}$ Kohri et al. ${ }^{28}$ and Wang et al. ${ }^{30}$ similarly prepared non-iridescent coatings via spray coating using polydopamine and melanin particles. However, such techniques have disadvantages in practical applications. Simple evaporation is a time-consuming process and it is difficult to prepare homogenous coatings on a large area and/or a curved surface. Although spray coating offers the benefits of rapid coating over a relatively large area on both planar and curved surfaces, it is still challenging to quickly coat an extremely large area or a surface with a complicated shape. In addition, there is certain concern about aerosols generated by the spray process. In this process, paint materials are dispersed and suspended in the atmosphere long enough to influence the environment and human health. ${ }^{31}$ In contrast, electrophoretic deposition (EPD) is one of the most versatile procedures for coating large areas. ${ }^{32-34}$ The main advantage of EPD is that coating films can be prepared on various surfaces with complicated shapes in a much shorter time compared with the other coating techniques. In this process, charged particles are deposited on an electrode by applying a DC voltage. The process is useful for applying materials to any electrically conductive surface. The thickness of the coating films can be controlled by varying the EPD conditions, such as the applied voltage, deposition duration and concentration of the particle suspension. In addition, there is almost no possibility of generating aerosols, as it is a totally liquid-phase process. The EPD process has been widely applied to various fields in many industries. For example, it has been widely used to coat automobile bodies and parts, which have sizes on the order of meters and complicated shapes. ${ }^{32}$ However, despite the many advantages of the EPD process, there are few papers about structural color coating via the EPD process. $^{35}$

In this study, we describe a novel and simple procedure to create structural color coating films by the EPD process using $\mathrm{SiO}_{2}$ particles. Previously, Tatsumisago and colleagues ${ }^{36-39}$ developed the electrophoretic sol-gel deposition method, which is a combination of the sol-gel method for particle preparation and EPD of the sol-gel-derived particles to prepare thick coating films. The coating films prepared via the electrophoretic sol-gel deposition method consist of a colloidal array of monodisperse $\mathrm{SiO}_{2}$ particles. However, they investigated these EPD coating films only for thick films but not for use as coloration films. Herein, we investigate the influences of the EPD conditions, including the applied voltage, deposition duration, particle diameter and the addition of black additives, on the packing state of the $\mathrm{SiO}_{2}$ particles and the resulting structural color, as well as the texture, in detail. The $\mathrm{SiO}_{2}$ particle array obtained reveals both iridescent and non-iridescent structural colors depending on the applied voltage in the EPD process. The color can be tuned by simply adjusting the size of the $\mathrm{SiO}_{2}$ particles. Moreover, we attempted to apply a structural color coating to substances with complicated shapes, for example, stainless-steel forks, via the EPD process.

\section{EXPERIMENTAL PROCEDURES}

\section{Materials}

The monodisperse $\mathrm{SiO}_{2}$ particles (200, 240, 260, 300 and $360 \mathrm{~nm}$ in diameter) used in this study were purchased from Fuji Kagaku Corp., Osaka, Japan. The carbon black (CB) particles, kindly given as a gift by Tokai Carbon Co., Ltd., Tokyo, Japan, had an average particle diameter of $110 \mathrm{~nm}$. Water was purified using a Direct-Q UV water purification system (Millipore Corp., Billerica, MA, USA). All other chemicals used in this study were purchased at the highest purity available and used as received.

\section{Electrophoretic deposition}

$\mathrm{SiO}_{2}$ and $\mathrm{CB}$ particle dispersions for EPD (coating sols) were prepared as follows. $\mathrm{SiO}_{2}$ particles were dispersed in $1 \mathrm{wt} \% \mathrm{NH}_{4} \mathrm{OH}$ aqueous solution with stirring. The solution was placed in an ultrasonic water bath, to disperse the particles homogeneously, and ethanol was added after the $\mathrm{SiO}_{2}$ particles were dispersed completely. The molar ratio of $\mathrm{H}_{2} \mathrm{O}$ (in the $\mathrm{NH}_{4} \mathrm{OH}$ solution) to ethanol was 1:4. The amount of $\mathrm{SiO}_{2}$ particles added to the dispersions was $1 \mathrm{wt} \%$ and the total weight of the dispersions was $70 \mathrm{~g}$. The coating sol was obtained by the addition of a certain amount of $\mathrm{CB}$ to the dispersion. Photographic images of the $\mathrm{SiO}_{2}$ particle dispersion, $\mathrm{CB}$ dispersion and coating sol are provided in the Supplementary Figure S1. Indium-tin oxide (ITO)-coated glass plates were generally used as coating substrates, but stainless-steel forks were also employed to demonstrate coating on a substrate with a complicated structure. A stainless-steel spiral (SUS304) was used as the counter electrode. A schematic drawing of the EPD process is shown in Supplementary Figure S2. The coating substrate and the spiral were cleaned with ethanol in an ultrasonic bath and immersed in the coating sols. A constant DC voltage was applied between the two electrodes, i.e., the coating substrate and the spiral, using a power supply (Model PAN110-3A, Kikusui Electronics Corp., Yokohama, Japan), which induced an electrophoretic force on the negatively charged $\mathrm{SiO}_{2}$ and $\mathrm{CB}$ particles toward the anode substrate (the ITOcoated glass plate). After electrophoresis, the coated substrates were withdrawn from the sols at a constant speed of $2 \mathrm{~mm} \mathrm{~s}^{-1}$ and dried at room temperature in air.

\section{Characterizations}

Photographs showing the colors of the coatings were acquired using a digital camera. The arrangement of the $\mathrm{SiO}_{2}$ particles in the coating films was investigated using an scanning electron microscopy (SEM; S-4800, Hitachi High-Technologies Corp., Tokyo, Japan). The samples were coated with a Pt (or carbon) layer using a sputtering apparatus and the images were obtained with an SEM at $15 \mathrm{kV}$. The coating substrate was cut at a position $10 \mathrm{~mm}$ from the bottom of the substrate for cross-sectional SEM observation (see Supplementary Figure S3). The coating film was generally fixed with epoxy resin (Epok 812, Okenshoji Co., Ltd., Tokyo, Japan) before the substrate was cut. To obtain magnified images and two-dimensional (2D) fast Fourier transform (FFT) images, an ITO-coated quartz substrate was employed and heat treatment $\left(800^{\circ} \mathrm{C}, 5 \mathrm{~h}\right)$ was carried out before the substrate was cut (in this case, epoxy resin was not used). The 2D FFT images were obtained using image analysis software (ImageJ) and a UV-visible spectrometer (V-670, JASCO Corp., Tokyo, Japan) with an absolute reflectance measurement unit (ARMN-735, JASCO Corp.) employed to measure the relative reflectance spectra. Zeta-potentials of the $\mathrm{SiO}_{2}$ particles and $\mathrm{CB}$ were measured with an electrophoretic light scatterer equipped with a laser Doppler system (ELS-Z, Otsuka Electronics Co., Ltd., Osaka, Japan).

\section{RESULTS AND DISCUSSION}

The surface of an $\mathrm{SiO}_{2}$ particle is negatively charged and has an electrical double layer as a result of the dissociation of $\mathrm{SiOH}$ groups situated on the surface when the $\mathrm{SiO}_{2}$ particle is dispersed in polar solvent, such as water and/or alcohols. If the diffuse electrical double layer on each particle is thick, the repulsion force between the particles increases. Such $\mathrm{SiO}_{2}$ particle dispersion is favored to the formation of a close-packed arrangement of spherical particles with long-range order, that is, colloidal crystals, by a simple evaporation-driven self-assembly process. However, the preparation of a roughly packed arrangement of $\mathrm{SiO}_{2}$ particles (with short-range order but without long-range order), that is, a colloidal amorphous array, from a $\mathrm{SiO}_{2}$ particle dispersion is difficult by such a simple process because of the strong tendency to crystallize. ${ }^{21,40}$ The EPD process we have chosen here allows the fabrication of a colloidal amorphous array of $\mathrm{SiO}_{2}$ particles, because the assembly rate during the EPD process is relatively quick compared with that during the simple evaporation process. First, we describe the appearance of EPD coating films 
a

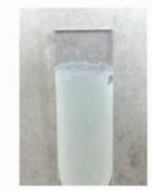

0

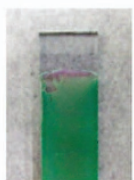

$3.6 \times 10^{-3}$

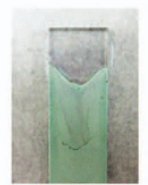

$1.2 \times 10^{-3}$

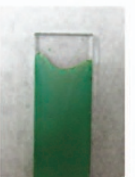

$4.8 \times 10^{-3}$

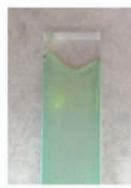

$2.4 \times 10^{-3}$

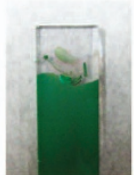

$6.0 \times 10^{-3}$ b

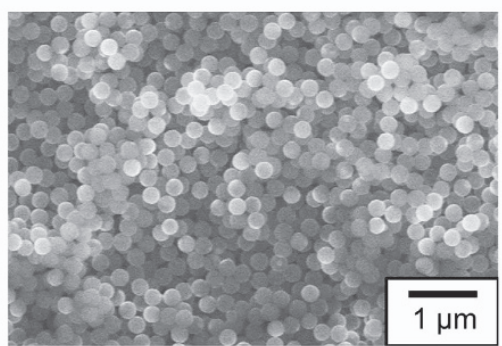

C

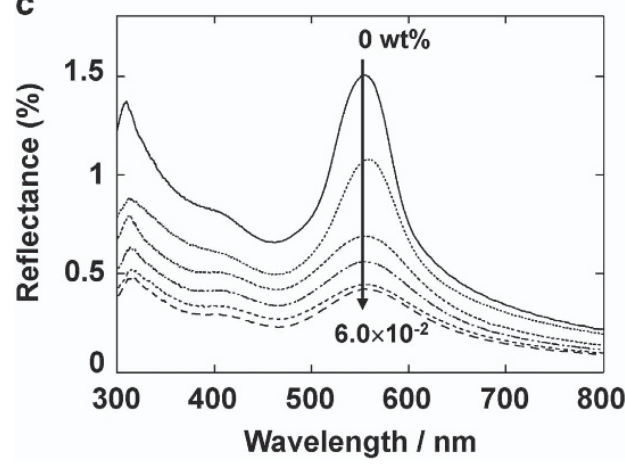

Figure 1 (a) Optical photographs of EPD coating films prepared using $\mathrm{SiO}_{2}$ particles with a diameter of $260 \mathrm{~nm}$ on an ITO-coated glass substrate. The quantity of $\mathrm{CB}$ added to the coating sol was varied from 0 to $6.0 \times 10^{-3}$ wt\% and the applied voltage and deposition time were $50 \mathrm{~V}$ and $2 \mathrm{~min}$, respectively. (b) Surface SEM image of the EPD coating film prepared using $\mathrm{SiO}_{2}$ particles with a diameter of $260 \mathrm{~nm}$ on an ITO-coated glass substrate $(0 \mathrm{wt} \% \mathrm{CB})$. (c) Reflection spectra of the coating films shown in a.

composed of only monodisperse $\mathrm{SiO}_{2}$ particles. Here, because the isoelectric point of $\mathrm{SiO}_{2}$ is $c a$. 2, we employed $1 \mathrm{wt} \% \mathrm{NH}_{4} \mathrm{OH}$ aqueous solution for the coating sol to obtain enough surface charge for the $\mathrm{SiO}_{2}$ particles. The zeta-potential of $\mathrm{SiO}_{2}$ particles under these conditions is $c a$. $-60 \mathrm{mV}$. Therefore, anodic deposition can be carried out in our system. Figure 1a shows an optical photograph of the EPD coating film on an ITO-coated glass substrate. $\mathrm{SiO}_{2}$ particles with diameters of $260 \mathrm{~nm}$ were used. The applied voltage and deposition time are $50 \mathrm{~V}$ and $2 \mathrm{~min}$, respectively. A homogeneous coating of the EPD film on the substrate was confirmed in the optical photograph. When $\mathrm{CB}$ was not added to the coating sol, the coating film had a faint structural color and appeared almost white to the naked eye. To confirm the arrangement of particles, we visualized the microstructure of the coating films using an SEM, as shown in Figure $1 \mathrm{~b}$. The $\mathrm{SiO}_{2}$ particles on the surface of the coating films did not appear to have crystallized. The microstructure of the coating film
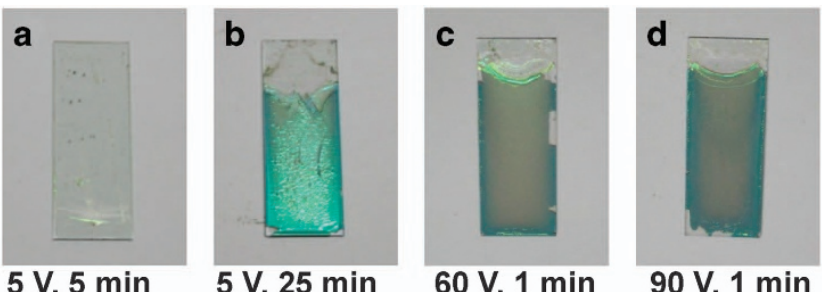

$5 \mathrm{~V}, 5 \mathrm{~min}$

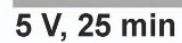

$60 \mathrm{~V}, 1 \mathrm{~min}$

$90 \mathrm{~V}, 1 \mathrm{~min}$
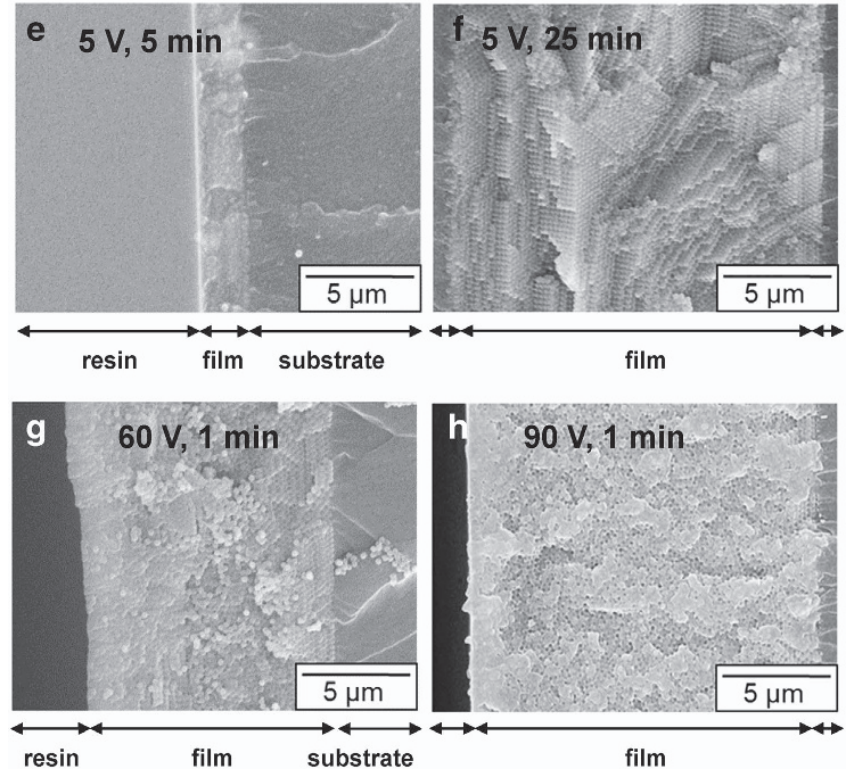

Figure 2 (a-d) Optical photographs and (e-h) cross-sectional SEM images of the EPD-coating films prepared using $\mathrm{SiO}_{2}$ particles with a diameter of $240 \mathrm{~nm}$ on ITO-coated glass substrates. The coating sol contained $3.6 \times 10^{-3} \mathrm{wt} \% \mathrm{CB}$. The applied voltages and deposition times were (a, e) $5 \mathrm{~V}$ and $5 \mathrm{~min},(\mathbf{b}, \mathbf{f}) 5 \mathrm{~V}$ and $25 \mathrm{~min},(\mathbf{c}, \mathbf{g}) 60 \mathrm{~V}$ and $1 \mathrm{~min}$, and (d, h) $90 \mathrm{~V}$ and 1 min, respectively. Samples for cross-sectional SEM observation were prepared by cutting coated films covered with epoxy resin.

is a colloidal amorphous array of $\mathrm{SiO}_{2}$ particles. Short-range order in the colloidal amorphous arrays causes coherent light scattering and thus structural color appears. However, the colors emitted from these arrays are very pale because the incoherent light scattering across the entire visible region is very strong. Therefore, the coating films prepared by the EPD process have whitish, faint structural colors even when the film is composed of monodisperse $\mathrm{SiO}_{2}$ particles. To reduce the contribution of incoherently scattered light to the overall scattering spectrum and to enhance the structural color of the colloidal amorphous arrays, black components, which absorb light uniformly across the entire visible region, can be incorporated into the films. ${ }^{41}$ $\mathrm{CB}$ is one of the most common and environmentally preferable black substances and reflects very little light in the visible region of the spectrum. ${ }^{21,42}$ Optical models of the structural color from amorphous arrays of colloidal particles incorporated with $\mathrm{CB}$ have been welldiscussed in our previous papers. ${ }^{21,26}$ Therefore, we added CB to the $\mathrm{SiO}_{2}$ particle dispersion and employed this 'coating sol' for the preparation of the EPD coating films. The average size of $\mathrm{CB}$ is ca. $110 \mathrm{~nm}$. The zeta-potential of $\mathrm{CB}$ is $c a .-80 \mathrm{mV}$. Therefore, co-deposition of $\mathrm{CB}$ with the $\mathrm{SiO}_{2}$ particles on the anodes is expected. The amount of $\mathrm{CB}$ added to the coating sol was varied. The applied voltage and deposition time of EPD were fixed at $50 \mathrm{~V}$ and $2 \mathrm{~min}$, respectively. Optical photographs of the EPD coating films obtained by varying the amount of added $\mathrm{CB}$ are shown in Figure 1a. The 


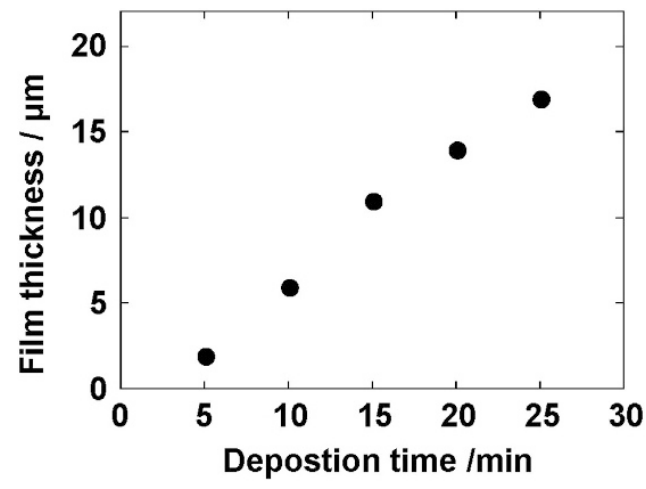

Figure 3 Thickness of the EPD-coating films as a function of deposition time. The coating films were prepared using $\mathrm{SiO}_{2}$ particles with a diameter of $240 \mathrm{~nm}$ on an ITO-coated glass substrate. The coating sol contained $3.6 \times 10^{-3} \mathrm{wt} \% \mathrm{CB}$ and the applied voltage was fixed at $5 \mathrm{~V}$.

coating films exhibit a bright green color. The color saturation of the coating films was found to greatly increase with $\mathrm{CB}$ incorporation. Quantitative reflectance spectra were obtained (Figure 1c). The overall magnitude of the reflectance greatly decreased with CB incorporation, whereas the intensity of the peak component seemed to be stable. Here we employed an absolute reflectance measurement system. In this system, the percentage of reflectance is estimated by comparison with the intensity of the light source. Therefore, the values of absolute reflectance become low. These values are comparable to those of our previous samples measured by the same system. ${ }^{23,27}$ When $3.6 \times 10^{-3}$ wt $\%$ CB was added to the coating sol, the most vivid green color was observed from the EPD film. However, the color of the coating films darkened when additional $\mathrm{CB},>4.8 \times 10^{-3} \mathrm{wt} \%$, was added to the coating sol. Therefore, we fixed the concentration of $\mathrm{CB}$ for the coating sols to $3.6 \times 10^{-3} \mathrm{wt} \%$ in the following experiments. The coating films formed with $\mathrm{SiO}_{2}$ particles and $\mathrm{CB}$ have a colloidal amorphous array structure that is almost the same as that formed without CB (figure not shown). The added $\mathrm{CB}$ was not observed in the SEM images, because a relatively low concentration of small-size $\mathrm{CB}$ was incorporated into the coating films.

Next, we investigated the effects of the applied voltage and deposition time of the EPD process on the thickness and microstructure of the coating films. First, the effects of the deposition duration for low applied voltage conditions were examined. Figure 2 shows optical photographs and SEM images of the EPD-coated films on ITO-coated glass substrates prepared with different applied voltages and deposition times. Here, $\mathrm{SiO}_{2}$ particles with a diameter of $240 \mathrm{~nm}$ were used. First, the applied voltage was fixed at $5 \mathrm{~V}$. The duration of the deposition was varied from 5 to $25 \mathrm{~min}$. Samples for crosssectional SEM observation were made by cutting coated films covered with epoxy resin to protect them from mechanical damage. The coating film obtained via EPD for $5 \mathrm{~min}$ is almost transparent and it is difficult to observe any structural color (Figure 2a). Judging from the cross-sectional SEM image, the morphology of the film is homogeneous in the direction of depth. The interface between the coating film and the ITO-coated glass substrate indicates good contact. The thickness of the film is $<2 \mu \mathrm{m}$ (Figure 2e). It appears that the film is too thin for the generation of incoherent light scattering. In contrast, a brilliant green color was observed in the coating film obtained via EPD for 25 min (Figure 2b). It can be observed that the coating film prepared via EPD with a low applied voltage has an iridescent structural color. The cross-sectional SEM image reveals
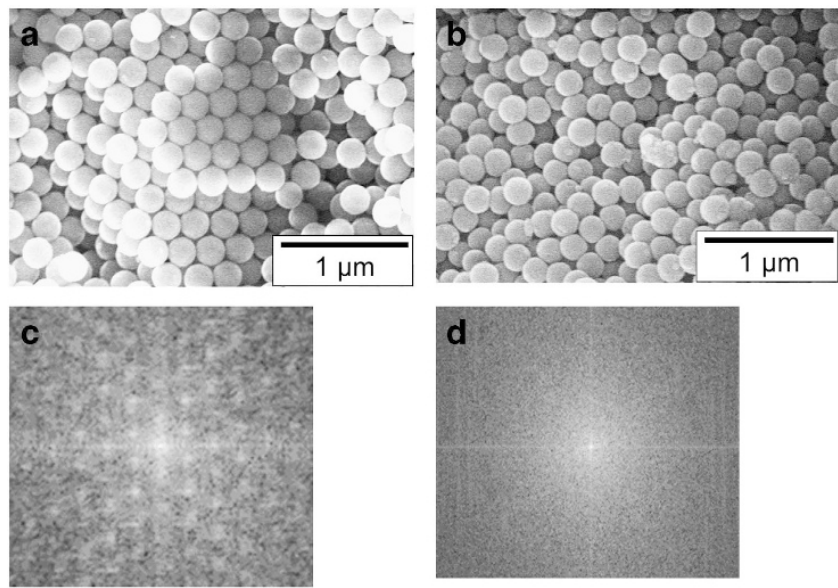

Figure $4(\mathbf{a}, \mathbf{b})$ Cross-sectional SEM images of EPD-coating films prepared using $\mathrm{SiO}_{2}$ particles with a diameter of $240 \mathrm{~nm}$ on ITO-coated quartz substrates. The coating sol contained $3.6 \times 10^{-3} \mathrm{wt} \% \mathrm{CB}$. The samples were heat treated at $800{ }^{\circ} \mathrm{C}$ for $5 \mathrm{~h}$ before SEM observation. (c, d) Twodimensional Fourier power spectra from the SEM images. The EPD coatings were applied at (a, c) $5 \mathrm{~V}$ for $25 \mathrm{~min}$ and (b, d) $90 \mathrm{~V}$ for $1 \mathrm{~min}$.

that the thickness of the film is $c a .17 \mu \mathrm{m}$ (Figure 2f). The coating film is organized into a close-packed arrangement of $\mathrm{SiO}_{2}$ particles with long-range order, that is, a colloidal crystal structure. The colloidal crystal diffracts light at a particular wavelength and displays a brilliant structural color based on Bragg reflection in the visible region. Therefore, an iridescent green color was observed in this coating film. We also examined various deposition times. The thickness of the film increases almost linearly with increasing deposition time (Figure 3 and Supplementary Figure S4). Colloidal crystal structures can be observed in the cross-sectional SEM images of EPD films prepared over any duration (Supplementary Figure S4). Next, the effects of the applied voltage on the thickness and the particle arrangement of the coating films were examined. The deposition time was fixed at $1 \mathrm{~min}$. The applied voltage was varied from 60 to $90 \mathrm{~V}$ and the coating films prepared at both voltages have a vivid green structural color (Figures $2 \mathrm{c}$ and $\mathrm{d}$ ), with no differences in their appearance. In contrast to the coating film prepared at $5 \mathrm{~V}$ for $25 \mathrm{~min}$, these films exhibit a non-iridescent structural color. SEM images of the crosssection indicate that the thicknesses of the films are 11 and $16 \mu \mathrm{m}$, respectively (Figures $2 \mathrm{~g}$ and $\mathrm{h}$ ). The thickness of the films increases with applied voltage (Supplementary Figure S5). The close-packed arrangement of the $\mathrm{SiO}_{2}$ particles with long-range order cannot be observed in these images. Here we have obtained two types of coating films of similar thickness $(c a .16-17 \mu \mathrm{m})$, one prepared by the EPD process at a low applied voltage for a long deposition duration $(5 \mathrm{~V}, 25 \mathrm{~min})$ and the other at a high applied voltage for a short deposition duration $(90 \mathrm{~V}, 1 \mathrm{~min})$. They exhibit iridescent and non-iridescent structural color, respectively, even though both films were prepared from the same coating sol and have similar thicknesses. The origin of the difference in the iridescence of the structural color can be ascribed to the difference in the arrangement of the $\mathrm{SiO}_{2}$ particles in the coating films. To determine the periodicity of the $\mathrm{SiO}_{2}$ particle arrangement, we established an independent measurement of the ordering of these coating films using SEM combined with an image processing technique, that is, 2D FFT. The 2D FFT technique provides spatial information on the SEM image. Here, epoxy resin was not used because it interferes with 2D FFT. Therefore, to improve the mechanical strength, ITO-coated 
a

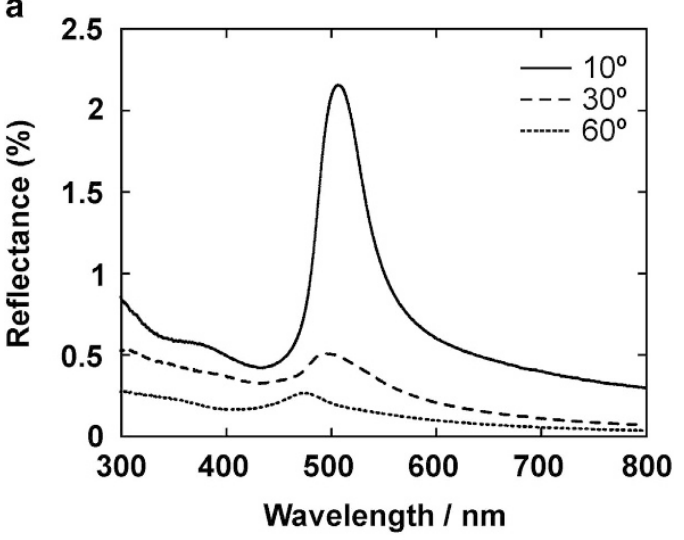

b

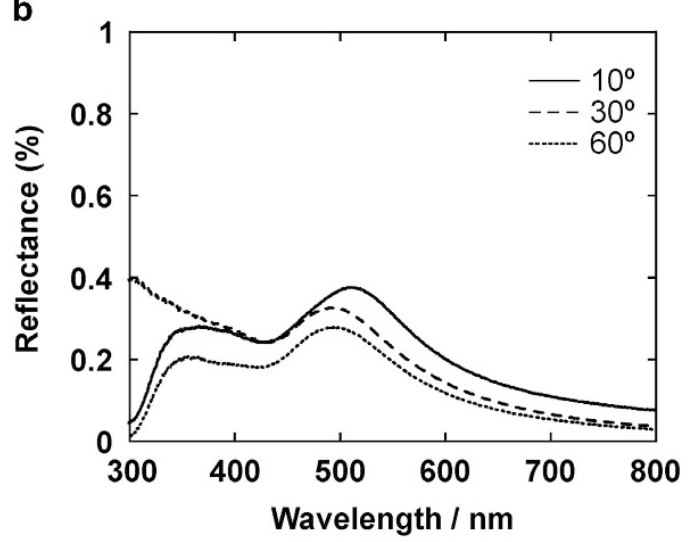

C

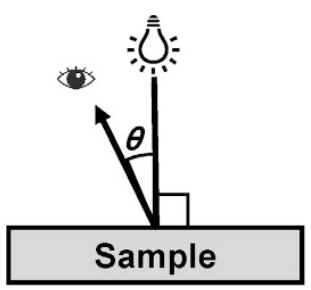

Figure 5 Reflection spectra of the coating films corresponding to a change in measurement angle. The incident angle relative to the normal of the planar surface of the membrane was $0^{\circ}$. The detection angles were $10^{\circ}, 30^{\circ}$ and $60^{\circ}$ relative to the normal of the planar surface of the coating films. The coating films were prepared using $\mathrm{SiO}_{2}$ particles with a diameter of $240 \mathrm{~nm}$ on ITO-coated glass substrates via the EPD process at (a) $5 \mathrm{~V}$ for $25 \mathrm{~min}$ and (b) $90 \mathrm{~V}$ for $1 \mathrm{~min}$. The coating sol contained $3.6 \times 10^{-3} \mathrm{wt} \% \mathrm{CB}$. (c) A schematic drawing of the measurement system is also given.

quartz substrates were employed instead of glass substrates and the coating films were heat treated at $800{ }^{\circ} \mathrm{C}$ for $5 \mathrm{~h}$ before SEM observation. A close-packed arrangement with long-range order was confirmed from the cross-sectional SEM image of the coating film prepared at $5 \mathrm{~V}$ for $25 \mathrm{~min}$ (Figure $4 \mathrm{a}$ ) and sharp hexagonal peaks appear in the corresponding 2D FFT image (Figure 4c). However, a disordered arrangement without long-range order appeared in the cross-sectional SEM image of the coating film prepared at $90 \mathrm{~V}$ for $1 \mathrm{~min}$ (Figure $4 \mathrm{~b}$ ) and only a broad circular pattern appeared in the corresponding 2D FFT image (Figure 4d). This finding indicates that the microstructure of the coating films composed of $\mathrm{SiO}_{2}$ particles is isotropic and exhibits short-range order. A similar trend was observed in the surface SEM images and their corresponding 2D FFT images a

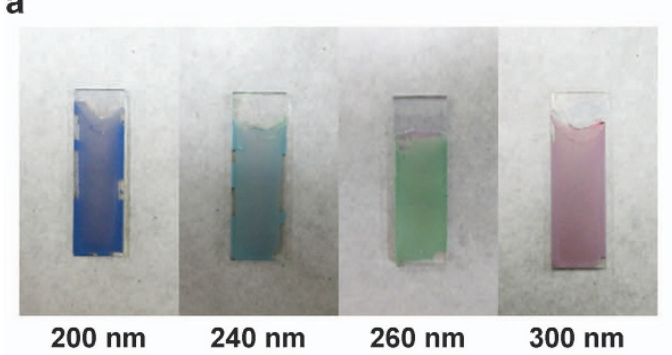

b

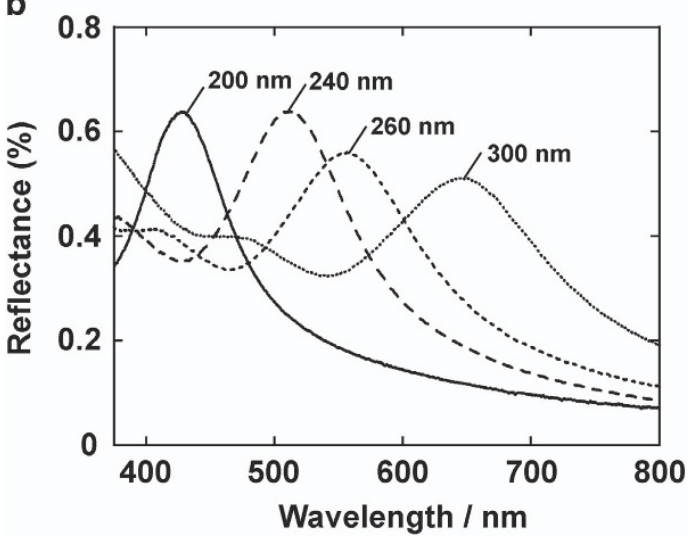

Figure 6 (a) Optical photographs of the coating films prepared using $\mathrm{SiO}_{2}$ particles with diameters of 200, 240, 260 and $300 \mathrm{~nm}$ on ITO-coated glass substrates via the EPD process at $50 \mathrm{~V}$ for $2 \mathrm{~min}$. The coating sols contained $3.6 \times 10^{-3}$ wt\% CB. (b) Reflection spectra of the coating films shown in a.

(Supplementary Figure S6). Under low applied voltage conditions, the attractive force between the particles and the anode is weak, and thus the electrophoresis rate of the $\mathrm{SiO}_{2}$ particles is slow. Under such conditions, the $\mathrm{SiO}_{2}$ particles tend to rearrange after deposition on the anode surface because there is sufficient time until the deposition of the next $\mathrm{SiO}_{2}$ particle monolayer. As a result of the rearrangement, a colloidal crystal array is generated. This mechanism is analogous to that for the formation of a colloidal crystal via the slow evaporation technique. ${ }^{11}$ In contrast, the attractive force between particles and the anode is very strong under high applied voltage conditions. The electrophoresis rate of the particles toward the anode is fast, and the deposited particles tightly adhere to the anode under such conditions. Therefore, the rearrangement of particles after deposition is prevented and a colloidal amorphous array is obtained. This mechanism is analogous to that for the formation of a colloidal amorphous array via the spray coating technique. ${ }^{21}$ To quantify the angle dependence of the structural color, we characterized the angleresolved optical properties of the coating films. The reflection spectra of the coating films depending on measurement angle are shown in Figure 5. The incident angle relative to the normal of the planar surface of the membrane was $0^{\circ}$. The detection angles were $10^{\circ}, 30^{\circ}$ and $60^{\circ}$ relative to the normal of the planar surface of the coating films (see schematic drawing in Figure $5 \mathrm{c}$ ). The position of the peak wavelengths in the reflection spectra $\left(\lambda_{\max }\right)$ for the coating films prepared under low applied voltage conditions appeared at $507 \mathrm{~nm}$ when the detection angle was $10^{\circ}$ and was shifted to $475 \mathrm{~nm}$ when the incident angle was $60^{\circ}$ (Figure 5a). The colloidal crystal diffracts light at a particular wavelength and displays brilliant structural color. The hue of such structural color shows variations that depend upon the viewing and light-illumination angles. ${ }^{43}$ Therefore, the large peak shift 


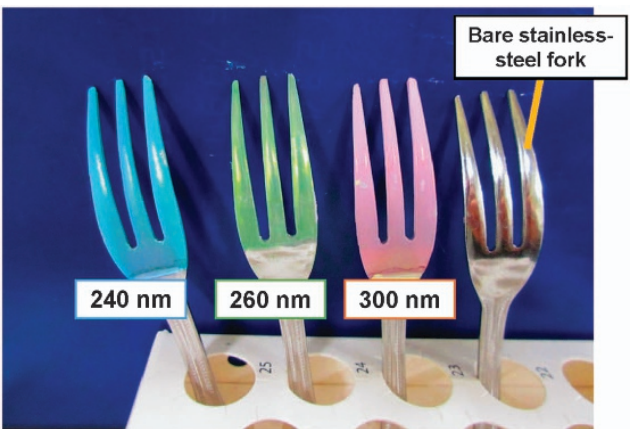

Figure 7 Optical photograph of the coating films prepared using $\mathrm{SiO}_{2}$ particles with diameters of 240,260 and $300 \mathrm{~nm}$ on stainless-steel forks via the EPD process. The coating sols contained $3.6 \times 10^{-3}$ wt\% CB.

should be attributed to the fact that the structural color is originated from the periodic structure of the coating film shown in Figure $4 \mathrm{c}$. For the coating films prepared under high applied voltage conditions, the position of $\lambda_{\max }$ shifts from $512 \mathrm{~nm}$ to $497 \mathrm{~nm}$ when the detection angle is varied from $10^{\circ}$ to $60^{\circ}$ (Figure $5 \mathrm{~b}$ ). The peak shift for this coating film in this range was unambiguously lower compared with that of the coating film prepared under low applied voltage. Here, the absolute reflectance value of the coating film prepared under low applied voltage conditions was relatively high when the detection angle was $10^{\circ}(>2 \%)$. The reflection intensity decreased drastically when the detection angle was varied to $30^{\circ}$ and $60^{\circ}(<0.5 \%)$ (Figure $\left.5 \mathrm{a}\right)$. In contrast, the absolute reflectance value of the coating film prepared under high applied voltage conditions was low $(<0.4 \%)$ and the change in reflection intensity is relatively small even when the detection angle was varied from $10^{\circ}$ to $60^{\circ}$ (Figure 5b). These tendencies correspond well to our previous samples of both colloidal crystal and amorphous arrays, measured by the same reflection system. $^{23}$ The coating film prepared via EPD at $50 \mathrm{~V}$ for $2 \mathrm{~min}$ also has a colloidal amorphous array structure, as shown in Figure 1b. The images were taken at angles different from the direction of incident light (Supplementary Figure S7). The color of the coating film is constant even when viewed from directions different from the direction of irradiation light. These results indicate that a high applied voltage $(>50 \mathrm{~V})$ is preferable for EPD to obtain a colloidal amorphous structure and non-iridescent structural color.

We also prepared EPD coating films using $\mathrm{SiO}_{2}$ particles with various diameters. The color of the coating films can be controlled by the diameter of the $\mathrm{SiO}_{2}$ particles employed in the EPD process. For example, as shown in Figure 6a, blue, blue-green, green and red coating films were prepared using different-sized particles. Figure $6 \mathrm{~b}$ shows the normalized reflection spectra of the coating films prepared using $\mathrm{SiO}_{2}$ particles with diameters of 200, 240, 260 and $300 \mathrm{~nm}$. The spectrum of the coating film prepared using $200 \mathrm{~nm} \mathrm{SiO}{ }_{2}$ particles, showing a deep blue color, features a clear reflection peak at $427 \mathrm{~nm}$. The reflection peak shifts to larger wavelengths proportional to the particle size, in accordance with previous reports. ${ }^{21}$ Blue-green $\left(\lambda_{\max }=513 \mathrm{~nm}\right)$, green $\left(\lambda_{\max }=557 \mathrm{~nm}\right)$ and red $\left(\lambda_{\max }=650 \mathrm{~nm}\right)$ colors were also obtained (also see Supplementary Figure S8). Because of the amorphous structure of the coating films, the colors do not depend on the observation angle during illumination. Thus, one promising way to obtain structural color coatings of various bright colors is the use of $\mathrm{SiO}_{2}$ particles with different diameters in the EPD method.
Finally, we attempted the application of EPD coatings with structural color on non-flat surfaces with complicated shapes, using stainless-steel forks as an example. Figure 7 shows the optical photographic of homogeneous EPD coating films on stainless-steel forks based on $\mathrm{SiO}_{2}$ particles with diameters of 240, 260 and $300 \mathrm{~nm}$, displaying brilliant blue, green and red colors, respectively. The impression of the color of the coating films on steel is different from that on ITO-coated glass. This can be attributed to the difference in light refection at the surface of the substrates. The advantage of the EPD technique is that homogeneous coatings can be fabricated even on surfaces with non-flat, large areas and complicated shapes. This result indicates that the advantages of the EPD technique can be exploited for structural color coatings.

\section{CONCLUSIONS}

In summary, we demonstrated for the first time that homogeneous structural color coatings consisting of monodisperse $\mathrm{SiO}_{2}$ particles can be successfully prepared by a simple EPD process. The thickness of the coating film can be controlled by varying the applied voltage and/or deposition time. Sufficient visibility of the structural color was achieved by the co-deposition of $\mathrm{CB}$ to reduce the contribution of incoherently scattered light to the overall scattering spectrum. When the EPD process is carried out under low applied voltage, a close-packed array of $\mathrm{SiO}_{2}$ particles that exhibits iridescent structural color is obtained. However, an amorphous packing state can be acquired under high applied voltage conditions. The structural color generated from such a coating film has low angle dependence. These results indicate that the arrangement of particles in the array and the iridescence of the resultant structural color can also be controlled by varying the EPD conditions. Various vividly colored coatings can be produced from $\mathrm{SiO}_{2}$ particles with diameters between 200 and $300 \mathrm{~nm}$. Moreover, coatings on materials with curved surfaces and complicated shapes, which are difficult to obtain with commonly used techniques, for example, the simple evaporation method, were also successfully prepared via the EPD process. This newly developed technique for the EPD of coating films of arrays composed of submicrometer-sized $\mathrm{SiO}_{2}$ particles and carbon substances produces environmentally friendly and nonfading paints that may have potential applications in various fields that currently use highly toxic heavy-metal-containing pigments. We expect this new paint coating technique to be used for decoration on a variety of surfaces, from small everyday items to large surfaces, such as automobiles.

\section{CONFLICT OF INTEREST}

The authors declare no conflict of interest.

\section{ACKNOWLEDGEMENTS}

This work was supported by JSPS KAKENHI Grant Numbers JP16K14388 and JP15H02200. This work is partly supported by the Center for Functional Nano Oxide at Hiroshima University.

1 Nassau, K. The Physics and Chemistry of Color: The Fifteen Causes of Color 2nd edn (John Wiley \& Sons, Inc.: New York, NY, USA, 2001).

2 Kuehni, R. G. Color: An Introduction to Practice and Principles 2nd edn (John Wiley \& Sons, Inc.: Hoboken, NJ, USA, 2005).

3 Yablonovitch, E. Inhibited spontaneous emission in solid-state physics and electronics. Phys. Rev. Lett. 58, 2059-2062 (1987).

4 Holtz, J. H. \& Asher, S. A. Polymerized colloidal crystal hydrogel films as intelligent chemical sensing materials. Nature 389, 829-832 (1997).

5 Srinivasarao, M. Nano-optics in the biological world: beetles, butterflies, birds, and moths. Chem. Rev. 99, 1935-1962 (1999). 
6 Fudouzi, H. \& Xia, Y. Colloidal crystals with tunable colors and their use as photonic papers. Langmuir 19, 9653-9660 (2003).

7 Kinoshita, S. \& Yoshioka, S. Structural colors in nature: the role of regularity and irregularity in the structure. ChemPhysChem 6, 1442-1459 (2005).

8 Zhao, Y., Xie, Z., Gu, H., Zhu, C. \& Gu, Z. Bio-inspired variable structural color materials. Chem. Soc. Rev. 41, 3297-3317 (2012).

9 Fu, Y., Tippets, C. A., Donev, E. U. \& Lopez, R. Structural colors: from natural to artificial systems. WIREs Nanomed. Nanobiotechnol. 8, 758-775 (2016).

10 Marlow, F., Muldarisnur, Sharifi, P., Brinkmann, R. \& Mendive, C. Opals: status and prospects. Angew. Chem. Int. Ed. 48, 6212-6233 (2009).

11 Jiang, P., Bertone, J. F., Hwang, K. S. \& Colvin, V. L. Single-crystal colloidal multilayers of controlled thickness. Chem. Mater. 11, 2132-2140 (1999).

12 Fudouzi, H. Tunable structural color in organisms and photonic materials for design of bioinspired materials. Sci. Technol. Adv. Mater. 12, 064704 (2011).

$13 \mathrm{Ge}$, J. \& Yin, Y. Responsive photonic crystals. Angew. Chem. Int. Ed. 50 1492-1522 (2011).

14 Prum, R. O., Torres, R. H., Williamson, S. \& Dyck, J. Coherent light scattering by blue feather barbs. Nature 396, 28-29 (1998).

15 Noh, H., Liew, S. F., Saranathan, V., Mochrie, S. G. J., Prum, R. O., Dufresne, E. R. \& Cao, H. How Noniridescent colors are generated by quasi-ordered structures of bird feathers. Adv. Mater. 22, 2871-2880 (2010).

16 Prum, R. O. \& Torres, R. H. Structural colouration of mammalian skin: convergent evolution of coherently scattering dermal collagen arrays. J. Exp. Biol. 207 2157-2172 (2004).

17 Dong, B. Q., Liu, X. H., Zhan, T. R., Jiang, L. P., Yin, H. W., Liu, F. \& Zi, J. Structural coloration and photonic pseudogap in natural random close-packing photonic structures. Opt. Express 18, 14430-14438 (2010).

18 Pouya, C., Stavenga, D. \& Vukusic, P. Discovery of ordered and quasi-ordered photonic crystal structures in the scales of the beetle Eupholus magnificus. Opt. Express 19, 11355-11364 (2011).

19 Takeoka, Y., Honda, M., Seki, T., Ishii, M. \& Nakamura, H. Structural colored liquid membrane without angle dependence. ACS Appl. Mater. Interfaces 1, 982-986 (2009).

20 Harun-Ur-Rashid, M., Imran, A. B., Seki, T., Ishii, M., Nakamura, H. \& Takeoka, Y. Angle-independent structural color in colloidal amorphous arrays. ChemPhysChem 11 , 579-583 (2010).

21 Takeoka, Y., Yoshioka, S., Takano, A., Arai, S., Nueangnoraj, K., Nishihara, H., Teshima, M., Ohtsuka, Y. \& Seki, T. Production of colored pigments with amorphous arrays of black and white colloidal particles. Angew. Chem. Int. Ed. 52 7261-7265 (2013).

22 Takeoka, Y., Yoshioka, S., Teshima, M., Takano, A., Harun-Ur-Rashid, M. \& Seki, T. Structurally coloured secondary particles composed of black and white colloidal particles. Sci. Rep. 3, 2371 (2013).

23 Hirashima, R., Seki, T., Katagiri, K., Akuzawa, Y., Torimoto, T. \& Takeoka, Y. Lightinduced saturation change in the angle-independent structural coloration of colloidal amorphous arrays. J. Mater. Chem. C 2, 344-348 (2014).

24 Takeoka, Y. Angle-independent structural coloured amorphous arrays. J. Mater. Chem 22, 23299-23309 (2012)

25 Takeoka, Y. Fusion materials for biomimetic structurally colored materials. Polym. J. 47, 106-113 (2015)

26 Yoshioka, S. \& Takeoka, Y. Production of colourful pigments consisting of amorphous arrays of silica particles. ChemPhysChem 15, 2209-2215 (2014).

27 Teshima, M., Seki, T., Kawano, R., Takeuchi, S., Yoshioka, S. \& Takeoka, Y. Preparation of structurally colored, monodisperse spherical assemblies composed of black and white colloidal particles using a micro-flow-focusing device. J. Mater. Chem. C 3, 769-777 (2015).

28 Kohri, M., Nannichi, Y., Taniguchi, T. \& Kishikawa, K. Biomimetic non-iridescent structural color materials from polydopamine black particles that mimic melanin granules. J. Mater. Chem. C 3, 720-724 (2015).
29 Xiao, M., Li, Y., Allen, M. C., Deheyn, D. D., Yue, X., Zhao, J., Gianneschi, N. C., Shawkey, M. D. \& Dhinojwala, A. Bio-inspired structural colors produced via self-assembly of synthetic melanin nanoparticles. ACS Nano 9, 5454-5460 (2015).

30 Wang, F., Zhang, X., Lin, Y., Wang, L. \& Zhu, J. Structural coloration pigments based on carbon modified $\mathrm{ZnS@SiO}_{2}$ nanospheres with low-angle dependence, high color saturation, and enhanced stability. ACS Appl. Mater. Interfaces 8, 5009-5016 (2016).

31 Vitayavirasuk, B., Junhom, S. \& Tantisaeranee, P. Exposure to lead, cadmium and chromium among spray painters in automobile body repair shops. J. Occup. Health 47 518-522 (2005).

32 Van der Biest, O. O. \& Vandeperre, L. J. Electrophoretic deposition of materials. Annu. Rev. Mater. Sci. 29, 327-352 (1999).

33 Corni, I., Ryan, M. P. \& Boccaccini, A. R. Electrophoretic deposition: from traditional ceramics to nanotechnology. J. Eur. Ceram. Soc. 28, 1353-1367 (2008).

34 Dickerson J. H. \& Boccaccini A. R. eds Electrophoretic Deposition of Nanomaterials, (Springer: New York, NY, USA, 2012).

35 Zhou, N., Zhang, A., Shi, L. \& Zhang, K.-Q. Fabrication of structurally-colored fibers with axial core-shell structure via electrophoretic deposition and their optical properties. ACS Macro Lett. 2, 116-120 (2013).

36 Nishimori, H., Tatsumisago, M. \& Minami, T. Preparation of thick silica films by the electrophoretic sol-gel deposition on a stainless steel sheet. J. Ceram. Soc. Jpn 103 , 78-80 (1995)

37 Hasegawa, K., Kunugi, S., Tatsumisago, M. \& Minami, T. Preparation of thick films by electrophoretic deposition using surface modified silica particles derived from sol-gel method. J. Sol-Gel Sci. Technol. 15, 243-249 (1999).

38 Matsuda, A., Tatsumisago, M. Handbook of Sol-Gel Science and Technology Vol. 1 , Ch.14 309-330 (ed Sakka S.) (Kluwer Academic Publishers: Norwell, MA, USA, 2004).

39 Matsuda, A., Tatsumisago, M. Sol-Gel Technologies for Glass Producers and Users Ch. 2.2.7, 83-88 (eds Aegerter M. A. \& Mennig M.) (Kluwer Academic Publishers: Norwell, MA, NY, USA, 2004).

40 García, P. D., Sapienza, R., Blanco, A. \& López, C. Photonic glass: a novel random material for light. Adv. Mater. 19, 2597-2602 (2007).

41 Shawkey, M. D. \& Hill, G. E. Significance of a basal melanin layer to production of non-iridescent structural plumage color: evidence from an amelanotic Steller's jay (Cyanocitta stelleri). J. Exp. Biol. 209, 1245-1250 (2006).

42 Forster, J. D., Noh, H., Liew, S. F., Saranathan, V., Schreck, C. F., Yang, L., Park, J. G., Prum, R. O., Mochrie, S. G. J., O'Hern, C. S., Cao, H. \& Dufresne, E. R. Biomimetic isotropic nanostructures for structural coloration. Adv. Mater. 22, 2939-2944 (2010).

43 Scheid, D., Lederle, C., Vowinkel, S., Schäfer, C. G., Stühn, B. \& Gallei, M. Redox- and mechano-chromic response of metallopolymer-based elastomeric colloidal crystal films. J. Mater. Chem. C 2, 2583-2590 (2014).

(i) This work is licensed under a Creative Commons Attribution 4.0 International License. The images or other third party material in this article are included in the article's Creative Commons license, unless indicated otherwise in the credit line; if the material is not included under the Creative Commons license, users will need to obtain permission from the license holder to reproduce the material. To view a copy of this license, visit http:// creativecommons.org/licenses/by/4.0/

(C) The Author(s) 2017

Supplementary Information accompanies the paper on the NPG Asia Materials website (http://www.nature.com/am) 